\title{
Experimental infection of Bama miniature pigs with a highly virulent classical swine fever virus
}

\author{
Yuan Sun ${ }^{\dagger}$, Qian Jiang ${ }^{\dagger}$, Da-Yong Tian, Huan Lin, Hong Li, Qiu-Ying Han, Wen Han, Chang-De Si, Shou-Ping Hu, \\ Zhuo Zhang, Lian-Dong Qu* and Hua-Ji Qiu*
}

\begin{abstract}
Background: Currently, larger domestic pigs are only animals widely used in vaccine evaluation and pathogenicity study of classical swine fever virus (CSFV). This study was aimed to create an alternative animal experimental infection model of CSFV.

Results: Twenty specific-pathogen-free Bama miniature pigs were randomly divided into two groups and rooms, infected and non-infected, and the pigs in the infected group were inoculated intramuscularly with $10^{4}, 10^{5}$ or $10^{6}$ $\mathrm{TCID}_{50}$ (median tissue culture infective dose) CSFV Shimen strain $(n=5 \times 3)$ or left uninoculated to serve as incontact pigs $(n=3)$. The uninfected control pigs $(n=2)$ were housed in a separate room. Clinical signs, body temperature, viraemia, tissue antigen distribution, pathological changes and seroconversion were monitored. Clinical signs were observed as early as 2 days post-inoculation (dpi) in all infected pigs (though mild in contact pigs), but not non-infected control pigs. All inoculated pigs showed viraemia by $6 \mathrm{dpi}$. The in-contact pigs showed lower levels of viraemia. At $10 \mathrm{dpi}$, seroconversion was noted in five of the 15 inoculated pigs. All inoculated or one in-contact pigs died by $15 \mathrm{dpi}$.
\end{abstract}

Conclusions: These results show that Bama miniature pigs support productive CSFV infection and display clinical signs and pathological changes consistent with CSFV infections observed in larger domestic pigs.

Keywords: Bama miniature pigs, classical swine fever virus, infection model

\section{Background}

Classical swine fever (CSF) is caused by classical swine fever virus (CSFV) and results in significant losses to the pig industry worldwide. CSFV belongs to the Pestivirus genus within the Flaviviridae family [1]. It is an enveloped virus containing a single-stranded, positive-sense RNA encoding a 3,898 amino acid polyprotein, which undergoes co- and post-translational processing by cellular and viral proteases to yield 11-12 cleavage products $[2,3]$.

Pigs are the natural host of CSFV, and are used as models for CSFV research. Therefore, vaccines against CSF should be evaluated exclusively in pigs in preclinical and clinical trials. A major challenge, however, is that domestic pigs are large and difficult to handle; thus,

\footnotetext{
* Correspondence: qld@hvri.ac.cn; huajiqiu@hvri.ac.cn

† Contributed equally

State Key Laboratory of Veterinary Biotechnology, Harbin Veterinary Research Institute, Chinese Academy of Agricultural Sciences, Harbin 150001, China
}

a convenient animal model is required for the study of CSF and other swine diseases. Several minipig strains, such as Göttingen, CLAWN, Yucatan, Lanyu, Bama, Sinclair and Hanford, have been used as toxicological and pharmacological models. Minipigs have also been used as a model for experimental infections for some pathogens including Escherichia coli [4], Streptococcus suis [5], Schistosoma japonicum [6], and dengue virus [7]. Chinese Bama miniature pigs are genetically stable, highly inbred, and small (adult mean body weight, 40 $\mathrm{kg}$ ) [8-10]. The animals are easy to handle compared to larger domestic pigs. In addition, it is feasible to take repeated samples of sufficient volume to enable vaccine studies. This makes the breed an excellent model for use in study on cardiovascular and gastrointestinal diseases, Helicobacter pylori infection, renal disease, skin pharmacology, and xenotransplantation [11,12]. The small size of the animals makes them ideal an infection model and an attractive alternative to larger domestic
C Biomed Central

(c) 2011 Sun et al; licensee BioMed Central Ltd. This is an Open Access article distributed under the terms of the Creative Commons Attribution License (http://creativecommons.org/licenses/by/2.0), which permits unrestricted use, distribution, and reproduction in any medium, provided the original work is properly cited. 
pigs, especially for long-term trials. Recently, specificpathogen-free (SPF) Bama miniature pig populations have been established in China as experimental animals for medical and veterinary applications.

To the best of our knowledge, there are no published reports on Bama miniature pigs experimentally infected with CSFV. This study details the results of experiments in which Bama miniature pigs were experimentally infected with the highly virulent Shimen strain of CSFV.

\section{Results}

\section{Clinical features of experimentally-infected Bama miniature pigs}

Previous studies showed that domestic pigs challenged with $10^{5}$ TCID $_{50}$ CSFV Shimen strain exhibited severe clinical signs typical of CSF [13]. Therefore, in the present study, Bama miniature pigs were inoculated i.m. with different doses of $\operatorname{CSFV}\left(10^{4}, 10^{5}\right.$ or $\left.10^{6} \mathrm{TCID}_{50}\right)$. The results showed that all pigs in groups $\mathrm{A}$ (infected with $\left.10^{4} \mathrm{TCID}_{50}\right), \mathrm{B}\left(10^{5} \mathrm{TCID}_{50}\right)$, and $\mathrm{C}\left(10^{6} \mathrm{TCID}_{50}\right)$ showed clinical signs (fever, shivering and anorexia) at 2 (groups A and B) and 3 (group C) days post-inoculation (dpi), accompanied by a significant increase in rectal temperature. The clinical outcomes for each pig following viral challenge are summarised in Table 1 . The incidence of fever was significantly higher in group A than in group $C(P<0.05)$; however, no obvious difference was observed between groups A and B. These early clinical signs were followed by loss of appetite, lethargy, stiffness of gait, reddening of the conjunctiva and loose stools or diarrhoea. As the disease progressed the clinical scores were $>6$, and the pigs began to die at $13 \mathrm{dpi}$. Notably, no reddening, haemorrhage, or petechiae were observed in the three in-contact animals before $10 \mathrm{dpi}$. These in-contact pigs initially displayed mild clinical signs at $10 \mathrm{dpi}$. Surprisingly, the clinical scores were very low prior to death. Death occurred from 9 dpi in groups $\mathrm{A}, \mathrm{B}$, and $\mathrm{C}$. At $15 \mathrm{dpi}$, the survival rates in groups $\mathrm{A}, \mathrm{B}, \mathrm{C}, \mathrm{D}$ and $\mathrm{E}$ were $0 / 5,0 / 5,0 / 5,2 / 3$ and $2 / 2$, respectively (Figure 1). The control pigs in group $\mathrm{E}$ remained healthy throughout the trial.

\section{Antibody responses to CSFV infection}

At $7 \mathrm{dpi}$, no anti-CSFV antibodies were detectable in any of the pigs. At $10 \mathrm{dpi}$, the pigs began to seroconvert: one in group A (antibody blocking rate, $43.7 \%$ ), one in group B (45\%) and two in group C (51.3\% and 64\%). At $15 \mathrm{dpi}$, one more pig in group B seroconverted (43.5\%).

\section{Viraemia and viral RNA distribution in the tissues of experimentally infected pigs}

Serum samples collected prior to inoculation and at 0,1 , 3, 7, 10 and $15 \mathrm{dpi}$ and tissues collected at necropsy were tested for viral RNA using the real-time RT-PCR as described previously. Viral RNA was detected in the serum of all pigs (except non-infected controls) at $3 \mathrm{dpi}$, with the viral loads peaking between 7 to $10 \mathrm{dpi}$ (Table 2). Animals inoculated with $10^{6} \mathrm{TCID}_{50}$ CSFV Shimen strain developed early and severe clinical signs and showed higher viral RNA loads (up to $10^{6}$ copies $/ \mu \mathrm{L}$ ) than the other inoculated animals. The in-contact pigs developed fewer clinical signs and became viraemic 10 dpi. The viral RNA load was $<10^{5}$ copies/ $\mu \mathrm{L}$ (Table 2 ). The CSFV RNA load in the different tissues was also examined. Generally, the viral load was higher in pigs challenged with $10^{4} \mathrm{TCID}_{50}$ than in the other pigs. Higher level viral RNA was detected in the lymph nodes, tonsils, spleen, and lung than in the urinary bladder and stomach (Figure 2). The level of viral RNA in the tissues of pigs challenged with $10^{4} \mathrm{TCID}_{50} \mathrm{CSFV}$ was significantly higher than that in pigs challenged with $10^{5} \mathrm{TCID}_{50}$ or $10^{6} \mathrm{TCID}_{50}$ or in-contact pigs $(P<$ 0.01 ). There was no difference between groups $B, C$ and D (Figure 2). No viral RNA was detected in the two uninfected control pigs.

\section{Pathological and histopathological findings}

Pigs died of infection were, subjected to pathological and histopathological examination following standard operational procedures, and any observed lesions recorded. All the surviving pigs were euthanised at 15 dpi and also subjected to pathological and histopathological examination. Inoculated pigs showed lesions typical

Table 1 Clinical outcome of the pigs following viral challenge.

\begin{tabular}{lllll}
\hline Groups & No. of animals with fever $\left(\geq \mathbf{4 0 . 5 ^ { \circ } \mathbf { C } )}\right.$ & No. of days to fever onset & Fever frequency during the trial & Survival rates \\
\hline A & $5 / 5$ & 2 & $26 / 56$ & $0 / 5$ \\
B & $5 / 5$ & 2 & $21 / 51$ & $0 / 5$ \\
C & $5 / 5$ & 3 & $18 / 58$ & $0 / 5$ \\
D & $3 / 3$ & 10 & $3 / 11$ & $2 / 3$ \\
E & O/2 & - & $0 / 30$ & $2 / 2$ \\
\hline
\end{tabular}

Twenty specific-pathogen-free Bama miniature pigs were randomly divided into five groups. Groups A, B and C $(n=5)$ were inoculated i.m. with $10^{4}, 10^{5}$ and $10^{6}$ $\mathrm{TCID}_{50}$ CSFV Shimen strain, respectively. Three non-inoculated pigs were housed in the same pen and served as in-contact animals. Two uninfected control pigs were housed in a separate pen. Clinical outcome, fever frequency and survival rates after viral challenge were calculated. 


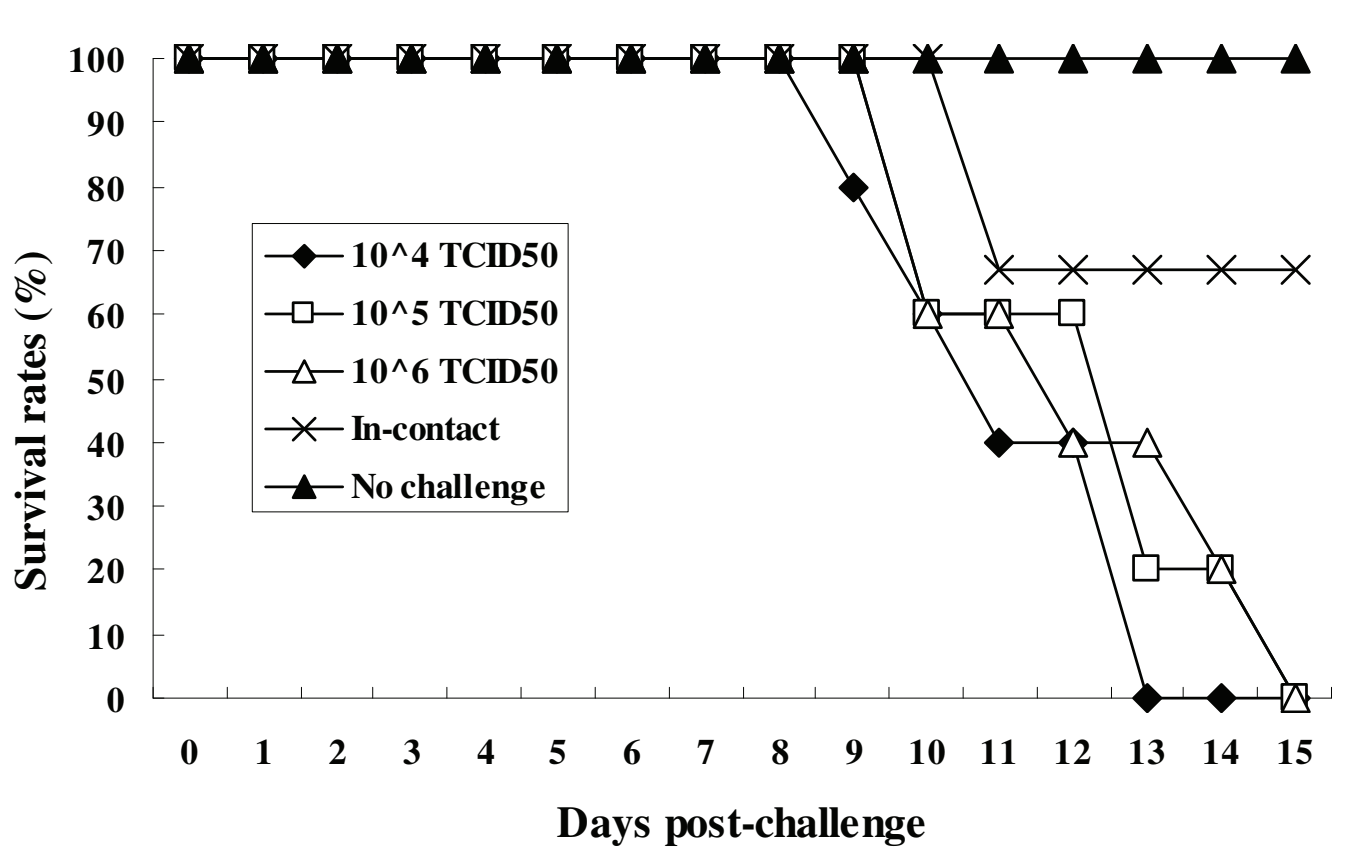

Figure 1 Survival rates of pigs challenged with different doses of CSFV. Groups A, B and C $(n=5)$ were inoculated i.m. with $10^{4}, 10^{5}$ and $10^{6} \mathrm{TCID}_{50}$ CSFV Shimen strain, respectively. Three non-inoculated pigs were housed in the same pen and served as in-contact animals. Two uninfected control pigs were housed in a separate pen.

Table 2 Detection of viral RNA in serum samples from challenged pigs by real-time RT-PCR (copies/ $\mu \mathrm{L})$.

\begin{tabular}{lcccccc}
\hline No. & \multicolumn{5}{c}{ Days post-challenge } \\
\cline { 2 - 7 } & $\mathbf{0}$ & $\mathbf{1}$ & $\mathbf{3}$ & $\mathbf{7}$ & $\mathbf{1 0}$ & $\mathbf{1 5}$ \\
\hline A1 & - & - & $2.51 \times 10^{3}$ & $1.44 \times 10^{4}$ & $1.78 \times 10^{4}$ & $/$ \\
A2 & - & - & $1.69 \times 10^{4}$ & $8.50 \times 10^{3}$ & $2.47 \times 10^{4}$ & $/$ \\
A3 & - & - & $8.19 \times 10^{3}$ & $1.12 \times 10^{4}$ & $1.06 \times 10^{4}$ & $/$ \\
A4 & - & - & $1.15 \times 10^{4}$ & $2.56 \times 10^{4}$ & $1.33 \times 10^{4}$ & $/$ \\
A5 & - & - & $7.45 \times 10^{3}$ & $5.55 \times 10^{4}$ & $/$ & $/$ \\
\hline B1 & - & - & $2.22 \times 10^{5}$ & $6.60 \times 10^{4}$ & $7.05 \times 10^{5}$ & $/$ \\
B2 & - & - & $6.01 \times 10^{4}$ & $3.70 \times 10^{5}$ & $2.38 \times 10^{5}$ & $/$ \\
B3 & - & - & $1.94 \times 10^{5}$ & $1.44 \times 10^{5}$ & $5.23 \times 10^{5}$ & $6.70 \times 10^{5}$ \\
B4 & - & - & $1.10 \times 10^{5}$ & $1.43 \times 10^{5}$ & $/$ & $/$ \\
B5 & - & - & $1.19 \times 10^{5}$ & $9.35 \times 10^{4}$ & $3.46 \times 10^{5}$ & $/$ \\
\hline C1 & - & - & $6.55 \times 10^{5}$ & $2.21 \times 10^{6}$ & $/$ & $/$ \\
C2 & - & - & $7.56 \times 10^{5}$ & $9.57 \times 10^{5}$ & $1.49 \times 10^{6}$ & $/$ \\
C3 & - & - & $1.16 \times 10^{6}$ & $1.23 \times 10^{6}$ & $1.06 \times 10^{6}$ & $2.31 \times 10^{6}$ \\
C4 & - & - & $4.24 \times 10^{5}$ & $1.13 \times 10^{6}$ & $2.63 \times 10^{6}$ & $/$ \\
C5 & - & - & $3.95 \times 10^{5}$ & $1.44 \times 10^{4}$ & $/$ & $/$ \\
\hline D1 & - & - & $3.81 \times 10^{4}$ & $1.35 \times 10^{4}$ & $7.79 \times 10^{5}$ & $5.40 \times 10^{5}$ \\
D2 & - & - & $2.65 \times 10^{3}$ & $6.67 \times 10^{3}$ & $3.07 \times 10^{4}$ & $/$ \\
D3 & - & - & $3.98 \times 10^{3}$ & $8.05 \times 10^{5}$ & $2.21 \times 10^{4}$ & $5.53 \times 10^{5}$ \\
\hline E1 & - & - & - & - & - & - \\
E2 & - & - & - & - & - & - \\
\hline SEr & & & & & & $/$ \\
\hline
\end{tabular}

Serum samples were collected prior to inoculation and at 1, 3, 7, 10 and 15 dpi and tested for viral RNA using the real-time RT-PCR as described previously (Zhao et al., 2008). of CSF, such as pinpoint haemorrhaging in the kidney or haemorrhaging within the lymph nodes and urinary bladder, necrosis in the tonsils, and splenic infarcts. Such lesions are typical in larger domestic pigs infected with CSFV. There were also obvious lesions in the liver and lungs and the stomach showed large areas of haemorrhage and ulcers. Although no obvious clinical signs were observed in the in-contact pigs, there was evidence of specific CSF-induced pathological changes. The scores for the pathological changes in each group are shown in Table 3. Infected pigs also showed severe haemorrhaging within the stomach, intestinal tract and mesentery. Surprisingly, the pathological changes observed in the pigs challenged with $10^{4} \mathrm{TCID}_{50}$ were more severe than those in the other pigs (data not shown).

Samples were fixed in buffered formalin, embedded in paraffin wax and stained with H\&E for histopathological examination. The most common histopathological findings in the challenged and in-contact animals were mild to severe lymphoid depletion, accompanied by hyperaemia and haemorrhage. Differing degrees of lymphoid depletion were also observed in the spleen. Perivascular cuffing, due to inflammatory lymphohistiocytic infiltrates, was frequently observed in the liver and kidney. The uninfected control animals showed no obvious changes. A composite analysis using the histopathological scoring system was performed, which yielded a mean 


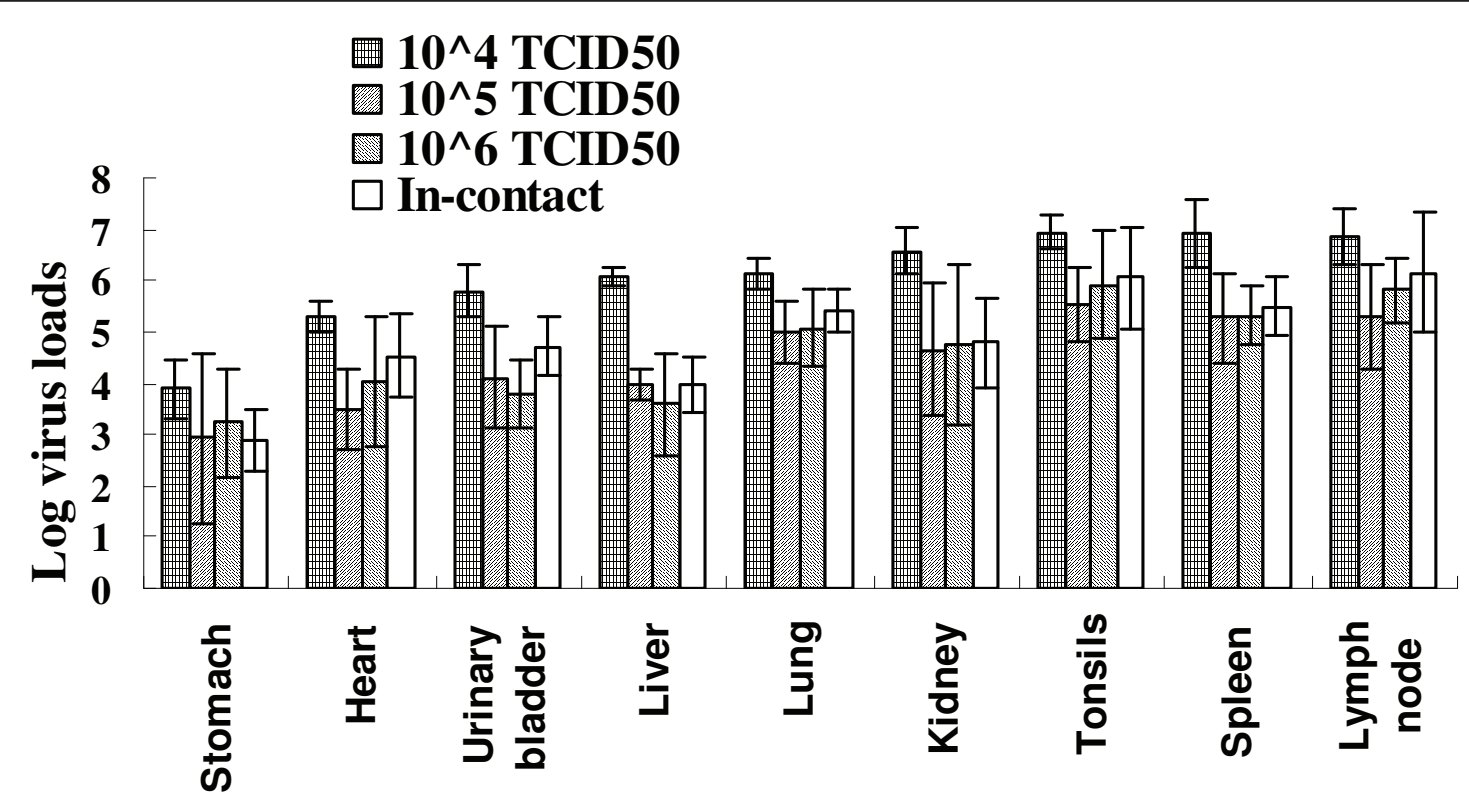

Figure $\mathbf{2}$ Log number of viral RNA copies from challenged pigs quantified using real-time RT-PCR (copies/ $\mu$ L). Heart, liver, spleen, lung, kidney, stomach, urinary bladder, tonsils and lymph nodes were collected and the distributions of CSFV RNA determined.

histopathological score of 15.67 in group A, 15.4 in group B, 17 in group C and 17.75 in group D (Table 4). These data indicate that the histopathological changes seen in the pigs in groups $C$ and $D$ were more severe than those in groups A and B. No statistically significant differences were observed between the challenged pigs and the in-contact animals.

\section{Discussion}

This study was aimed to develop a Bama miniature pig model of CSFV infection and to use this model to study CSFV pathogenesis. The ultimate aim is to use the model to evaluate new CSF vaccines. Developing alternative porcine models with different susceptibility to CSFV would be highly beneficial, as it would help to increase our knowledge of the molecular mechanisms involved in resistance/susceptibility to the virus. This may then, potentially, lead to breeding for enhanced
CSF-resistance using marker-assisted selection, an important step toward disease control.

In this study, Bama miniature pigs were inoculated i. $\mathrm{m}$. with different doses of CSFV Shimen strain, which is highly virulent in larger domestic pigs causing severe CSF [13]. The results showed that Bama miniature pigs are highly susceptible to CSFV, and infected pigs developed specific CSF clinical signs. These clinical signs were mostly consistent with those observed in experimentally infected domestic pigs. Marked CSF clinical signs appeared $2 \mathrm{dpi}$ and persisted until the end of the trial. Like domestic pigs, the Bama miniature pigs showed marked fever, with the peak temperature being $42^{\circ} \mathrm{C}$. There were also specific clinical signs of CSF, such as loss of appetite, lethargy, stiffness of gait and oedema. Pronounced pathological changes were also observed in the tissues and organs, including haemorrhaging in the kidney, lymph nodes and urinary bladder

Table 3 Average scores for the pathological changes observed in challenged Bama miniature pigs.

\begin{tabular}{lllllllllll}
\hline Groups & Heart & Liver & Spleen & Lung & Kidney & Stomach & Bladder & Lymph Nodes & Tonsils & Total \\
\hline A & 1.7 & 2.0 & 3.0 & 1.7 & 2.3 & 1.3 & 2.3 & 2.0 & 2.3 & 2.3 \\
B & 2.7 & 2.7 & 3.0 & 2.3 & 2.0 & 1.7 & 2.0 & 2.3 & 3.0 & 21.7 \\
C & 2.0 & 2.5 & 3.0 & 2.5 & 2.5 & 2.0 & 2.0 & 2.5 & 3.0 & 22.0 \\
D & 2.5 & 2.5 & 3.0 & 2.5 & 2.5 & 2.5 & 3.0 & 2.5 & 3.0 & 24.0 \\
E & 0.0 & 0.0 & 0.0 & 0.0 & 0.0 & 0.0 & 0.0 & 0.0 & 0.0 & 0.0 \\
\hline
\end{tabular}

Extended scoring systems for clinical symptoms and pathology were used allowing the detailed characterisation of the diseases and lesions (Everett et al., 2010). Heart, liver, spleen, lung, kidney, stomach, bladder, tonsils and lymph nodes were collected from pigs that died from the infection or were euthanised at the end of the trial. Examinations followed standard operational procedures and any observed lesions were recorded. A gross pathological scoring system was used incorporating 10 parameters. Each parameter was scored from 0 (no lesion) to 3 (severe lesion). 
Table 4 Average scores for the histopathological changes observed in challenged Bama miniature pigs.

\begin{tabular}{lllllllllll}
\hline Groups & Heart & Liver & Spleen & Lung & Kidney & Stomach & Bladder & Lymph nodes & Tonsils & Total \\
\hline A & 0.33 & 1.83 & 2 & 2 & 1.83 & 0.67 & 2 & 2.67 & 2.33 & 15.67 \\
B & 0 & 1.8 & 2.8 & 2.4 & 1.2 & 1.2 & 1.2 & 2.4 & 2.4 & 15.4 \\
C & 0 & 1.6 & 2.8 & 2.4 & 2.4 & 0.8 & 1.8 & 3 & 2.2 & 17 \\
D & 1 & 2 & 2.75 & 1.75 & 2 & 1.75 & 1.75 & 2.5 & 2.25 & 17.75 \\
E & 0 & 0 & 0 & 0 & 0 & 0 & 0 & 0 & 0 & 0 \\
\hline
\end{tabular}

Samples were fixed in buffered formalin and embedded in paraffin wax. Sections were prepared and stained with H\&E for histopathological examination. A histopathological scoring system incorporating seven parameters was used and the severity of the lesions was scored from 0 (no lesion) to 3 (severe lesion).

and necrosis in the tonsils and spleen, similar to that observed in domestic pigs infected with CSFV [13]. Unexpectedly, more severe pathological changes, higher fever frequency, and higher virus load were observed in $10^{4}$ TCID $_{50}$ group. The possible explanations may be: 1 ) The infected animals were housed in the same room and direct transmission between different dose groups are likely to occur; 2) The three doses studied all exceed the minimum lethal dose of the virus, thus dose effects were not revealed; 3) The differences are not statistically significantly different in most cases. To define the dosedependent pathogenicity, smaller doses should be included in future study. Notably, the results of the present study revealed obvious differences between domestic pigs and Bama miniature pigs in terms of pathological changes in the alimentary tract. Infected miniature pigs showed severe haemorrhaging in the digestive tract, including the stomach, intestinal tract and mesentery, which are mild or absent in domestic pigs. Possibly, there may be slight differences in tissue tropism of CSFV between the two pig species, or just an occasional case. A more detailed comparative pathology study is needed to clarify the possible pathogenicity differences. No obvious clinical signs of CSF were observed in the in-contact pigs prior to death; although CSFinduced pathological changes, consistent with those observed in domestic pigs, were noted. These results suggest that Bama miniature pigs are as susceptible to CSFV as domestic pigs. More research regarding CSFV replication, proliferation, pathogenesis and host interactions (such as cytokine induction) are required, as acute overproduction of some cytokines may play a key role in pathogenesis [14].

Taking the temperature of Bama miniature pigs is very difficult as they become agitated very easily. Therefore, traditional methods (i.e., measuring rectal temperature) are not suited to these animals. This means that the recorded temperatures may not be very accurate. Thus, a more simple and accurate method for taking the temperature of these pigs, such as biochips, should be used. The use of biochips for monitoring temperatures provides practical advantages in terms of easy monitoring, which reduces disturbance to the animals and allows more frequent measurement [15]. Also, it is very important to take the temperature at consistent time points, as these animals have a marked circadian rhythm [15].

\section{Conclusions}

Bama miniature pigs were infected with the highly virulent CSFV Shimen strain and subsequent infection/ transmission was monitored establishing an experimental challenge model for CSFV. Further work is required to establish whether this Bama miniature pig model can be used to evaluate the efficacy of CSFV vaccines.

\section{Materials and methods \\ Animals}

Twenty 120-day-old SPF Bama miniature pigs (body weight, 16-25 kg) were used in the study. All pigs were clinically healthy and maintained in the animal facility at Harbin Veterinary Research Institute under standard conditions prescribed by the Institutional Guidelines. The study protocol was approved by the Institutional Animal Care and Use Committee. Each group (except the control group) was placed in an individual pen in the same room. Prior to the study, all pigs were negative for CSFV antibodies and antigens as assessed by a CSFV antibody detection kit (IDEXX, Liebefeld-bern, Switzerland) and a TaqMan real-time RT-PCR [16].

\section{Virus}

The highly virulent CSFV Shimen strain [17] was propagated and titrated in PK-15 cells. Briefly, serial 10-fold dilutions $\left(10^{-1}\right.$ to $\left.10^{-10}\right)$ of the virus stock were prepared in Dulbecco's modification of Eagle's medium (DMEM) and used to infect PK-15 cells (seeded in 96-well plates on the previous day at a density of $10^{6}$ cells/well). Each dilution was assayed in duplicate $(100 \mu \mathrm{l} /$ well $)$. Mockinfections (cells not exposed to virus) were set up simultaneously. After $2 \mathrm{~h}$ of adsorption, the virus inoculum was drawn off and DMEM containing 2\% fetal bovine serum (FBS) added. The cells were then incubated at $37^{\circ} \mathrm{C}$ in a humidified $5 \% \mathrm{CO}_{2}$ incubator. On Day 3 postinfection, the cells were washed twice with phosphate buffered saline (PBS) and fixed for $8 \mathrm{~min}$ with cold acetone. The fixed cells were then incubated with the 
anti-E2 monoclonal antibody (mAb) HQ06 [18] for $1 \mathrm{~h}$ at $37^{\circ} \mathrm{C}$ in a humidified chamber followed by three washes with PBS. The cells were then incubated with fluorescein isothiocyanate (FITC)-labelled goat antimouse IgG (Sigma-Aldrich, Missouri, USA) for $45 \mathrm{~min}$ at $37^{\circ} \mathrm{C}$, followed by three washes with PBS. Finally, the cells were covered with $90 \%$ alkaline glycerine and examined under a fluorescence microscope (Nikon TE200, Japan).

\section{Animal inoculation}

The pigs were randomly divided into five groups. Groups A, B and C of five pigs each were housed in three pens of one room and inoculated intramuscularly (i.m.) with a 1-ml aliquot of CSFV Shimen strain at $10^{4}$, $10^{5}$ or $10^{6}$ median tissue culture infective dose $\left(\mathrm{TCID}_{50}\right)$, respectively. Group D of three pigs were not inoculated, but housed in the same room, serving as incontact infection controls. Group E comprised two uninfected control animals housed in a pen of a separate room. Standard disease parameters were determined as described previously [15]. Following viral challenge, rectal temperature and clinical signs (anorexia, depression, shivering, haemorrhage, constipation and diarrhoea) were recorded on a daily basis. The tonsils, spleen, kidney, liver, lung, urinary bladder and lymph nodes were harvested from the pigs after death (from infection or after euthanasia at the end of the trial) were collected for further immunohistochemical study and evaluation of pathological changes.

\section{Blocking ELISA}

To monitor seroconversion, serum samples were collected at 0, 3, 7, 10 and $15 \mathrm{dpi}$ and tested for CSFV-specific antibodies using the IDEXX HerdChek* CSFV Antibody Test Kit (IDEXX, Liebefeld-bern, Switzerland) according to the manufacturer's instructions.

\section{Real-time RT-PCR}

Serum samples were collected at $0,1,3,7,10$ and 15 dpi to measure the level of viraemia. Tissues and organs were also collected to determine the distribution of CSFV RNA. CSFV RNA was isolated using an RNA isolation kit (Qiagen, USA). CSFV RNA was quantified by real-time RT-PCR using the TaqMan System, primers and probes specific for CSFV, and an ABI 7700 Sequence Detector (PE Applied Biosystems, USA) as described previously [16]. A standard curve was constructed using known amounts of RNA diluted in salmon sperm RNA and used to determine the viral copy number. The detection limit of the PCR assay was 41.8 RNA copies per reaction with excellent linearity $(\mathrm{R}>$ 0.94) over five logs of RNA content. The samples were run in triplicates. For statistical purposes data were expressed as the logarithm mean.

\section{Pathology and histopathology}

An extended pathological and histopathological scoring system allowed detailed characterisation of pathological lesions [15]. Heart, liver, spleen, lung, kidney, stomach, urinary bladder, tonsils and lymph nodes were collected for pathological examination. Examinations followed standard operational procedures and any observed lesions were recorded. The gross pathology scoring system incorporated 10 parameters (body condition, skin and subcutis, tonsils, spleen, kidney, ileum and ileocecal valve, respiratory system, lymph nodes, urinary bladder and conjunctiva). Each parameter was scored from 0 (no lesion) to 3 (severe lesion). Samples were fixed in buffered formalin and embedded in paraffin wax. Sections $(4 \mu \mathrm{m})$ were stained with haematoxylin and eosin (H-E) for histopathological examination. A histopathological scoring system incorporating seven parameters (tonsils, spleen, lymph nodes, liver, lung, kidney and ileocaecal valve) was also developed, and the severity of the lesions scored from 0 (no lesion) to 3 (severe lesion). Data from both scoring systems were analysed using the Kruskal-Wallis non-parametric mean comparison test [19] and differences were considered significant at $P<0.05$.

\section{Acknowledgements}

This study was supported by the International Science and Technology Cooperation Project of China (2010DFB33910) and the National Science and Technology Support Program of China (2006BAD06A03).

\section{Authors' contributions}

YS, QJ, DYT, HL, CDS and HL carried out the study. QYH and WH carried out real-time RT-PCR. SPH and ZZ performed the pathological and histopathological detection. HJQ and LDQ designed the study and wrote the paper. All authors read and approved the final manuscript.

\section{Competing interests}

The authors declare that they have no competing interests.

Received: 13 July 2011 Accepted: 25 September 2011 Published: 25 September 2011

\section{References}

1. Fauquet CM, Mayo MA, Maniloff J, Desselberger U, Ball LA: ICTV: Virus Taxonomy: VIIIth Report of the International Committee on Taxonomy of Viruses. Elsevier Academic Press 2005.

2. Moser C, Stettler P, Tratschin JD, Hofmann MA: Cytopathogenic and noncytopathogenic RNA replicons of classical swine fever virus. J Virol 1999, 73:7787-7794.

3. Rijn van PA, Miedema GK, Wensvoort G, Gennip van HG, Moormann RJ: Antigenic structure of envelope glycoprotein E1 of hog cholera virus. $J$ Virol 1994, 68:3934-3942.

4. Bronner S, Murbach V, Peter JD, Levêque D, Elkhaïli H, Salmon Y, Dhoyen N, Monteil $H$, Woodnutt $G$, Jehl F: Ex vivo pharmacodynamics of amoxicillinclavulanate against $\beta$-lactamase-producing Escherichia coli in a Yucatan miniature pig model that mimics human pharmacokinetics. Antimicrob Agents Chemother 2002, 46:3782-3789. 
5. Madsen LW, Aalbaek B, Nielsen OL, Jensen HE: Aerogenous infection of microbiologically defined minipigs with Streptococcus suis serotype 2. A new model. APMIS 2001, 109:412-418.

6. Watanabe K, Kikuchi M, Ohno A, Mohamed RT, Nara T, Ubalee R, Senba M, Iwasaki T, Chen H, Aoki Y, Hirayama K: The miniature pig: a unique experimental model for Schistosoma japonicum infection. Parasitol Int 2004, 53:293-299.

7. Cassetti MC, Durbin A, Harris E, Rico-Hesse R, Roehrig J, Rothman A, Whitehead S, Natarajan R, Laughlin C: Report of an NIAID workshop on dengue animal models. Vaccine 2010, 28:4229-4234.

8. Wu FC, Wei H, Gan SX, Wang AD: Analysis of genetic diversity in Bama and Guizhou miniature pigs by RAPD. Shi Yan Sheng Wu Xue Bao 2001, 34:115-119, (in Chinese).

9. Liu HB, Lv PR, He RG, Yang XG, Qin XE, Pan TB, Huang GY, Huang MR, Lu YQ, Lu SS, Li DS, Lu KH: Cloned Guangxi Bama minipig (Sus scrofa) and its offspring have normal reproductive performance. Cell Reprogram 2010, 12:543-550.

10. Zhou J, Huang F, Hua X, Cui L, Zhang W, Shen Y, Yan Y, Chen P, Ding D, Mou J, Chen Q, Lan D, Yang Z: Inhibition of porcine transmissible gastroenteritis virus (TGEV) replication in mini-pigs by shRNA. Virus Res 2010, 149:51-55

11. Yu J, Wang Z, Wang B, Li HQ, Yi B, Yin WD: Study of lectin-like oxidized low-density lipoprotein receptor-1 expression in atherosclerotic of Guangxi Bama minture swine. Chin J Cardiovasc Rev 2007, 10:764-766.

12. Koga T, Shimada Y, Sato K, Takahashi K, Kikuchi I, Miura T, Takenouchi T, Narita T, Iwata M: Experimental Helicobacter pylori gastric infection in miniature pigs. J Med Microbiol 2002, 51:238-246.

13. Sun Y, Liu DF, Wang YF, Liang BB, Cheng D, Li N, Qi QF, Zhu QH, Qiu HJ: Generation and efficacy evaluation of a recombinant adenovirus expressing the E2 protein of classical swine fever virus. Res Vet Sci 2010 88:77-82.

14. Graham SP, Everett HE, Johns HL, Haines FJ, La Rocca SA, Khatri M, Wright IK, Drew T, Crooke HR: Characterisation of virus-specific peripheral blood cell cytokine responses following vaccination or infection with classical swine fever viruses. Vet Microbiol 2010, 142:34-40.

15. Everett H, Salguero FJ, Graham SP, Haines F, Johns H, Clifford D, Nunez A, La Rocca SA, Parchariyanon S, Steinbach F, Drew T, Crooke H: Characterisation of experimental infections of domestic pigs with genotype 2.1 and 3.3 isolates of classical swine fever virus. Vet. Microbiol 2010, 142:26-33.

16. Zhao JJ, Cheng D, Li N, Sun Y, Shi Z, Zhu QH, Tu C, Tong GZ, Qiu HJ: Evaluation of a multiplex real-time RT-PCR for quantitative and differential detection of wild-type viruses and C-strain vaccine of Classical swine fever virus. Vet Microbiol 2008, 126:1-10.

17. Yu X, Tu C, Li H, Hu R, Chen C, Li Z, Zhang M, Yin Z: DNA-mediated protection against classical swine fever virus. Vaccine 2001, 19:1520-1525.

18. Peng WP, Hou Q, Xia ZH, Chen D, Li N, Sun Y, Qiu HJ: Identification of a conserved linear B-cell epitope at the $\mathrm{N}$-terminus of the E2 glycoprotein of classical swine fever virus by phage-displayed random peptide library. Virus Res 2008, 135:267-272.

19. Elliott AC, Hynan LSA: SAS ${ }^{\oplus}$ ) macro implementation of a multiple comparison post hoc test for a Kruskal-Wallis analysis. Comput. Methods Programs Biomed 2011, 102:75-80.

\section{Submit your next manuscript to BioMed Central and take full advantage of:}

- Convenient online submission

- Thorough peer review

- No space constraints or color figure charges

- Immediate publication on acceptance

- Inclusion in PubMed, CAS, Scopus and Google Scholar

- Research which is freely available for redistribution

Submit your manuscript at www.biomedcentral.com/submit 